\title{
Preparation and flow characteristic of a novel phase change fluid for latent heat transfer
}

\author{
Deqiu Zou ${ }^{\mathrm{a}, \mathrm{b}, *}$, Ziping Feng ${ }^{\mathrm{b}}$, Rui Xiao ${ }^{\mathrm{b}}$, Kun Qin ${ }^{\mathrm{b}}$, Jianjun Zhang ${ }^{\mathrm{b}}$, Wenji Song ${ }^{\mathrm{b}}$, Qiu Tu ${ }^{\mathrm{b}}$ \\ ${ }^{a}$ Marine College of Ningbo University, Ningbo 315211, Zhejiang, China \\ ${ }^{\mathrm{b}}$ Guangzhou Institute of Energy Conversion, Chinese Academy of Sciences, Guangzhou 510640, China
}

\section{A R T I C L E I N F O}

\section{Article history:}

Received 24 November 2009

Received in revised form

30 May 2010

Accepted 29 July 2010

Available online 21 August 2010

Keywords:

Phase change emulsion (PCE)

Turbulent flow

Heat storage

Latent heat transfer

\begin{abstract}
A B S T R A C T
A novel phase change emulsion (PCE) was prepared and its latent heat was measured by DSC. To analyze its feasibility in heat transportation through a piping system, an experimental system was built. The pressure drop of the PCE for turbulent flow was measured and the effects of such facts as the paraffin concentration and flow velocity were discussed. According to the pressure characteristic and latent heat of the PCE, the pumping power consumption rates of PCE to water under the same pipe diameter and a given heat transportation quantity can be obtained. The results show that mass flow rate and pumping power consumption of the PCE decrease greatly compared with water. For example, the decrease can be up to about $73 \%$ at $V=0.6 \mathrm{~m} / \mathrm{s}$ ( 20 and $30 \mathrm{wt} \%$ ). Furthermore, the results show that PCE of $20 \mathrm{wt} \%$ can obtain almost the same pumping power consumption savings as PCE of $30 \mathrm{wt} \%$ in a certain flow velocity range. Finally, the applications of the PCE in the area of waste heat usage, electrical boiler and solar energy usage were commented.
\end{abstract}

(c) 2010 Elsevier B.V. All rights reserved.

\section{Introduction}

In recent years, research on paraffin as phase change material has attracted attention due to its applications in heat storage and energy transport systems [1-6]. However, research on phase change emulsion (PCE) was mainly focused on paraffin emulsion with low melting point, which is suitable for air conditioning or refrigerating. For example, Inaba et al. have prepared a PCE with tetradecane $\left(\mathrm{C}_{14} \mathrm{H}_{30}\right) \quad\left(\mathrm{Tm}=5.9{ }^{\circ} \mathrm{C}, \mathrm{Hm}=229 \mathrm{~kJ} / \mathrm{kg}\right)$ as phase change material (PCM) and studied the natural convection heat transfer of the microemulsion [7-9].Yang et al. [10] and Wang et al. 11] have prepared a tetradecane $/ \mathrm{H}_{2} \mathrm{O}$ emulsion and a new encapsulated tetradecane slurry. They have studied the turbulent heat transfer enhancement of the microencapsulated phase change slurries with constant wall heat flux. Chen et al. [12] have made an emulsion of micro-particles of $\mathrm{C}_{14} \mathrm{H}_{30}$ and water by using the phase incursion method (PIM). Hu and Zhang [13] have presented a novel insight for the forced convective heat transfer enhancement of microencapsulated phase change slurries flowing through a circular tube with constant heat flux. Zhao et al. [14,15] have prepared a $\mathrm{O} / \mathrm{W}$-type emulsion, and investigated the nonNewtonian rheologic characteristic and heat transfer performance of the emulsion. Royon and Guiffant [16] have prepared an

\footnotetext{
* Corresponding author at: Marine College of Ningbo University, Ningbo 315211, Zhejiang, China. Tel./fax: +8657487600137.

E-mail address: zoudq@ms.giec.ac.cn (D. Zou).
}

emulsion with alkanes as phase change material and its melting temperature being $9.5^{\circ} \mathrm{C}$.

Although researchers have carried out good work on PCE for cool storage, few investigations about PCE with melting temperature higher than $80^{\circ} \mathrm{C}$ for heat storage are available in the literature. PCE mentioned in this paper was made of microparticles of paraffin as phase change material (PCM) with the melting range from 80 to $90{ }^{\circ} \mathrm{C}$, water and surfactants. It is a category of novel phase change fluid as heat storage and transfer media in the heating system. PCE of 10,20 and $30 \mathrm{wt} \%$ were prepared and their characteristics were studied. Finally, the pumping power consumptions of a conventional (water) system and the PCE system were compared.

\section{Experiment for characteristics of PCE}

\subsection{Sample preparation}

PCE was prepared by phase incursion method (PIM). Phase change paraffin $\left(\mathrm{Tm}=87.0^{\circ} \mathrm{C}, \mathrm{Hm}=203.9 \mathrm{~kJ} / \mathrm{kg}\right.$ ), a commercial product, was used as phase change material (see Fig. 1). Mixture A is composed of paraffin and a lipophilic surfactant; mixture B is composed of deionized water and a hydrophilic surfactant; by adding different amounts of mixture B into mixture A dropwise at a certain temperature with stirring, the emulsion with different paraffin concentrations could be obtained. However, the possibility of agglomeration or precipitation of the emulsion particles 


\begin{tabular}{|c|c|c|c|}
\hline \multicolumn{2}{|c|}{ Nomenclature } & $\rho$ & density $\left(\mathrm{kg} / \mathrm{m}^{3}\right)$ \\
\hline$c$ & mass concentration (wt\%) & $V$ & flow velocity (m/s) \\
\hline$m$ & mass flow rate $(\mathrm{kg} / \mathrm{s})$ & $\Delta P$ & pressure drop $(\mathrm{Pa})$ \\
\hline$Q_{H}$ & latent heat of PCE $(\mathrm{J} / \mathrm{g})$ & $\eta$ & pump efficiency \\
\hline$q$ & heat transfer rate $(\mathrm{W})$ & & \\
\hline$\Delta t$ & temperature difference $\left({ }^{\circ} \mathrm{C}\right)$ & \multirow{2}{*}{\multicolumn{2}{|c|}{ Subscripts }} \\
\hline $\operatorname{Tm}$ & melting point $\left({ }^{\circ} \mathrm{C}\right)$ & & \\
\hline $\mathrm{Hm}$ & heat of fusion $(\mathrm{J} / \mathrm{g})$ & W & water \\
\hline C & specific heat $(\mathrm{J} / \mathrm{g} \mathrm{k})$ & $p$ & Phase change emulsion (PCE) \\
\hline$D$ & diameter duct (m) & & \\
\hline$Q$ & volume rate $\left(\mathrm{m}^{3} / \mathrm{s}\right)$ & & \\
\hline
\end{tabular}

exists, and the question of stability is always a main concern in the production of an emulsion. Agglomeration or precipitation of the emulsion particles can be prevented using the following measures: (1) reduce the diameter of the emulsion particles. The very small droplet size causes a large reduction in the gravity force, and the Brownian motion may be sufficient for overcoming gravity. The diameter of the emulsion particles can be reduced by optimizing emulsification condition such as emulsion agents, surfactant concentration, stirring rates, emulsification duration, etc., (2) seek a reasonable concentration of PCE. The PCE with higher concentration will cause agglomeration or precipitation more easily. However, reducing concentration will decrease the latent heat of the PCE. So, a reasonable concentration of PCE should be studied to obtain a PCE with the higher latent heat and the better stability. The mean volumetric diameter of the emulsion particles is $0.304 \mu \mathrm{m}$ ( $20 \mathrm{wt} \%$ ), and all the PCE with different concentrations do not agglomerate or precipitate in experiment.

Fig. 2 shows the external appearance of PCE. It is seen that it shows a white color and good fluidity.

\subsection{Latent heat measurement}

The latent heat of the PCE was recorded during the heating process using a differential scanning calorimeter (DSC). Indium was used as the standard for temperature calibration, and the analysis was performed at a constant stream of nitrogen. The heating rate was $10^{\circ} \mathrm{C} / \mathrm{min}$. The melting heat of the PCE of 10 , 20 and $30 \mathrm{wt} \%$ is 25,51 and $75 \mathrm{~kJ} / \mathrm{kg}$, respectively, as measured by DSC.

\subsection{Experimental apparatus for flow characteristic}

The experimental apparatus for studying the flow characteristic of the PCE is shown in Fig. 3. The major components of the system contain a PCE reservoir, water bath, blender, pump, an AC power supply, a test duct, a digital differential manometer and a flow meter. The PCE in the reservoir can be maintained at a constant temperature by the water bath in the reservoir. The blender was used to stir the PCE and make it uniform. The bypass pipe was used to adjust the flow rate.

Steel pipe, $1.2 \mathrm{~m}$ in length and $12.0 \mathrm{~mm}$ in inner diameter, was used as the test duct. There were two pressure measuring points, $0.85 \mathrm{~m}$ to the entrance and $0.12 \mathrm{~m}$ to the exit. The fluid flow could be regarded as fully developed flow between the two pressure

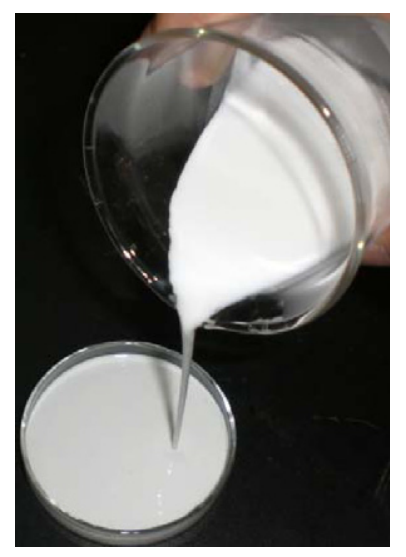

Fig. 2. External appearance of PCE.
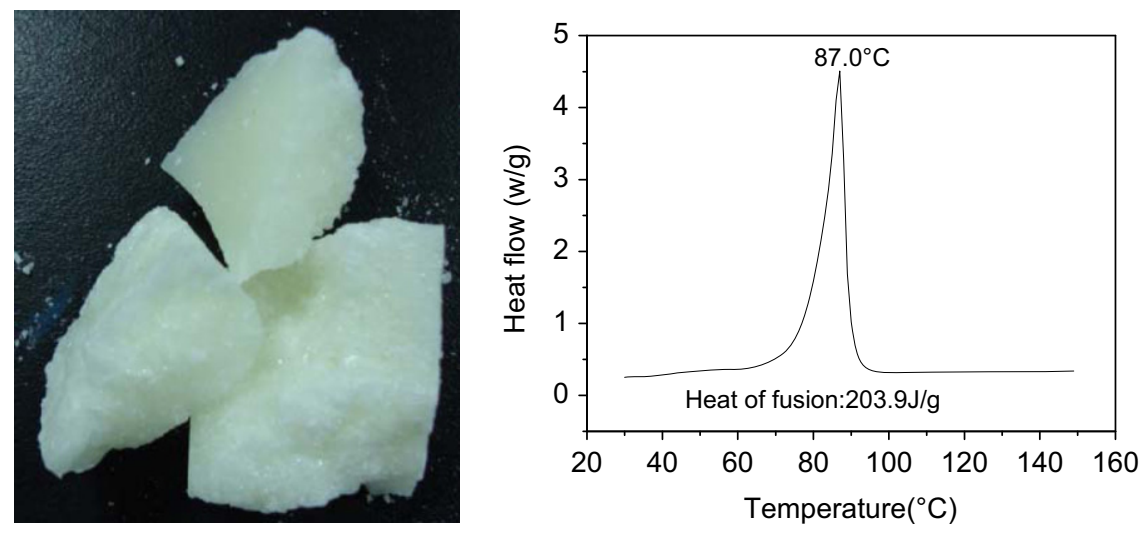

Fig. 1. Photo of phase change paraffin and its DSC curve. 


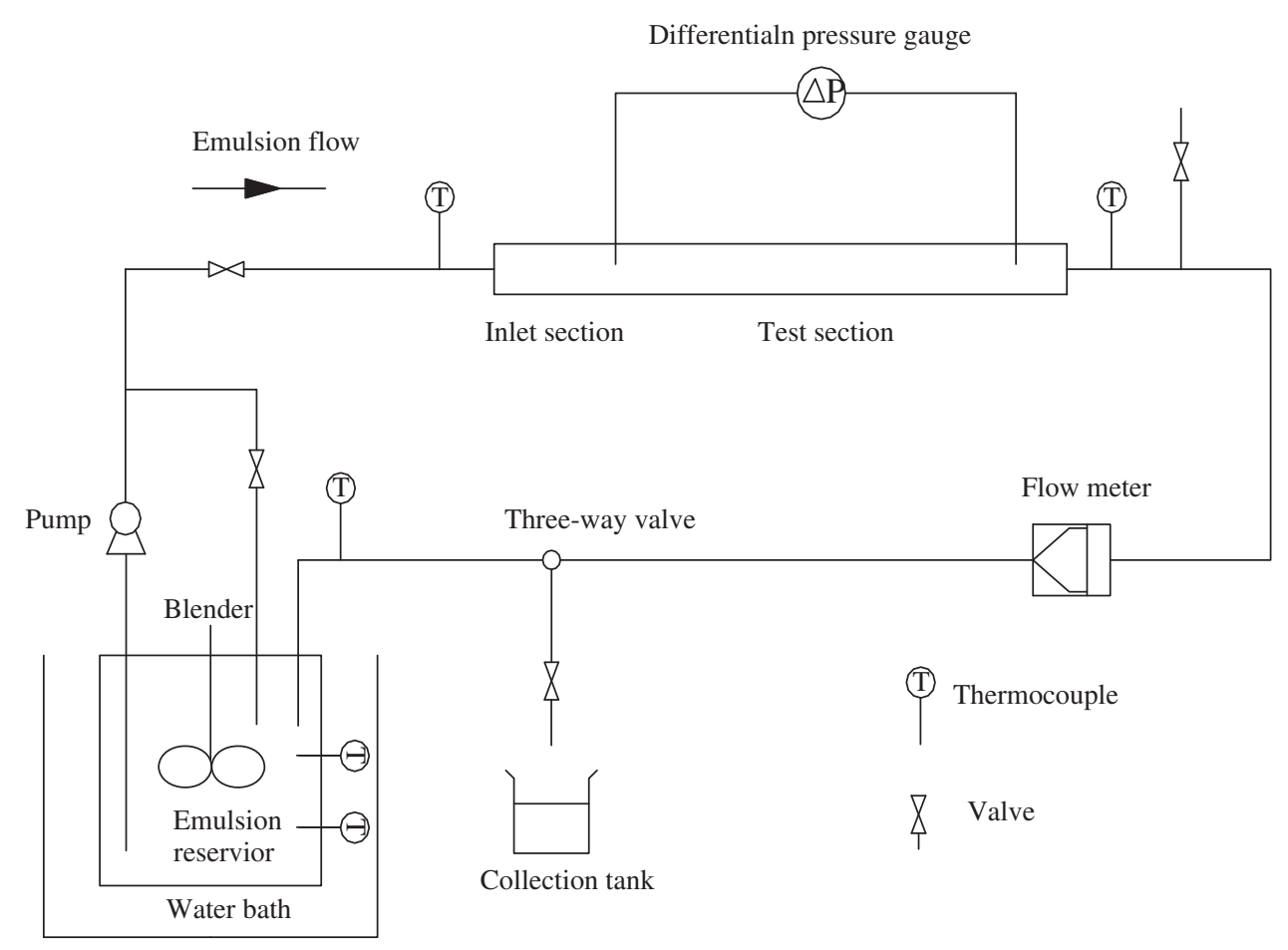

Fig. 3. Experimental system for flow characteristics.

measuring points. In order to decrease the influence of ambient temperature on the measured viscosity of the PCE, the test duct was thermally insulated. K-type thermocouples were set in the middle of the reservoir, at the entry and exit of the test duct. All thermocouples were calibrated and their measurement error was less than $0.1^{\circ} \mathrm{C}$. All the temperature data were recorded by a HP-34970A Data Logger.

The pressure drops were measured in the isothermal test section of the loop for water, PCE of 10, 20 and $30 \mathrm{wt} \%$ at 84,88 and $92{ }^{\circ} \mathrm{C}$, respectively. The pressure drop characteristic at different temperatures is shown in Fig. 4.

Fig. 4 shows that the pressure drop of the PCE increases with the velocity rise. It also increases with increase in concentration. However, PCE of 10 and $20 \mathrm{wt} \%$ have almost the same pressure drop value. The reason for this is that the viscosity does not increase much in the mass fraction range of $10-20 \mathrm{wt} \%$. Furthermore, the pressure drop at higher temperature was smaller. The reasons are the following: With the increase in temperature at the temperature range of $80-90{ }^{\circ} \mathrm{C}$, the paraffin melts gradually and changes from solid-phase, solid/liquid, twophase and liquid-phase. As we know, solid-phase paraffin has the largest viscosity value and decreases with the phase changing into liquid. So, the viscosity of the PCE decreases with the phase changing from solid-phase, solid/liquid two-phase and liquidphase. When temperature is higher than $90^{\circ} \mathrm{C}$, the paraffin changes into liquid-phase completely, the viscosity decreases and the pressure drop decreases.

\section{Results and discussion}

\subsection{Feasibility discussion}

In order to analyze the applicable feasibility of the PCE system, the pumping power consumptions of a conventional (water) system and a PCE system are compared.
To simulate a heating system, it is assumed that the working temperature range is $80-90^{\circ} \mathrm{C}$ for water system and PCE system. For a given heat transportation quantity and the same pipe diameter, the equivalent specific heat of the PCE can be calculated as follows:

$C_{p}=\frac{C_{w} \Delta t+Q_{H}}{\Delta t}$

The flow mass rate of PCE to that of water can be calculated as follows:

$\frac{m_{p}}{m_{w}}=\frac{q / C_{p} \Delta t}{q / C_{w} \Delta t}=\frac{C_{w}}{C_{p}}$

The flow volume rate of PCE to that of water can be calculated as follows:

$\frac{Q_{P}}{Q_{W}}=\frac{m_{P} / \rho_{P}}{m_{W} / \rho_{W}}=\frac{m_{P} \rho_{W}}{m_{W} \rho_{P}}$

All parameters of the PCE that are related to latent heat transfer in a pipe are listed in Table 1.

The pumping power consumption rate of PCE to that of water can be calculated as follows:

$\frac{N_{P}}{N_{W}}=\frac{Q_{P} \Delta P_{P} / \eta}{Q_{W} \Delta P_{W} / \eta}=\frac{v_{P} \Delta P_{P}}{v_{W} \Delta P_{W}}$

Fig. 5 indicates the relationship between pumping power consumptions rates and the flow velocity. From this, it is seen that: (1) the pumping power consumption of PCE is less than that of water. Unlike the sensible heat storage method, the latent heat storage method provides much higher storage density due to the latent heat of PCE. (2) PCE of 20 wt\% can obtain almost the same pumping power consumption savings as PCE of $30 \mathrm{wt} \%$. The reason is that the latent heat of PCE increases with the increase of concentration. However, the higher viscosity gives rise to a larger 
pressure drop, which makes pumping power consumption increase. (3) For a given concentration, there exists the largest pumping power consumption savings. For example, for the PCE of
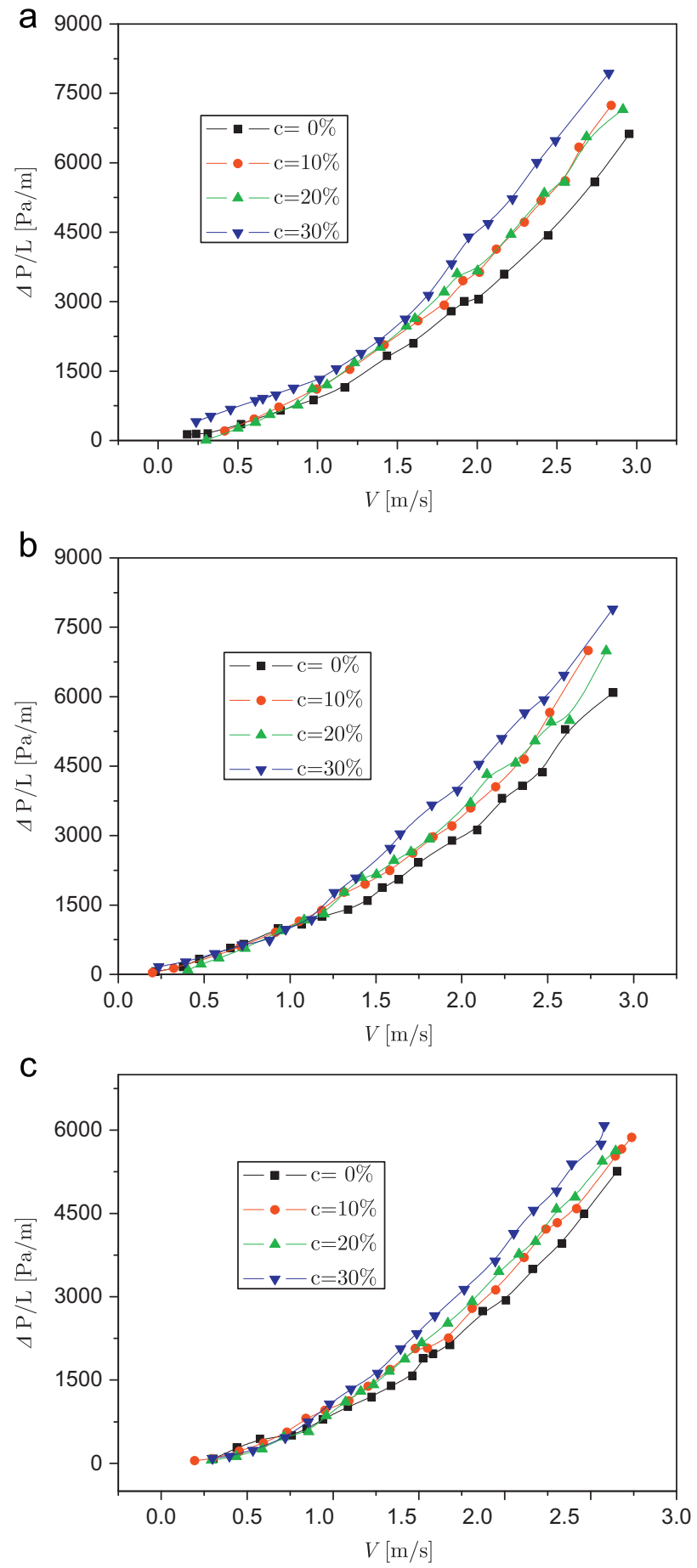

Fig. 4. Pressure drop versus velocity for PCE: (a) $84{ }^{\circ} \mathrm{C}$, (b) $88^{\circ} \mathrm{C}$ and (c) $92^{\circ} \mathrm{C}$.

Table 1

Parameters of PCE for latent heat transfer.

\begin{tabular}{llll}
\hline $\begin{array}{l}\text { Mass } \\
\text { fraction }(\%)\end{array}$ & $\begin{array}{l}\text { Heat of fusion } \\
(\mathrm{J} / \mathrm{g})\end{array}$ & $\begin{array}{l}\text { Equivalent specific } \\
\text { heat }(\mathrm{J} / \mathrm{g} \mathrm{K})\end{array}$ & $\begin{array}{l}\text { Volume } \\
\text { flow rate }\end{array}$ \\
\hline 10 & 25 & 6.7 & 0.650 \\
20 & 51 & 9.3 & 0.476 \\
30 & 75 & 11.7 & 0.387 \\
\hline
\end{tabular}

$20 \mathrm{wt} \%$ at $92{ }^{\circ} \mathrm{C}$, the optimum value approaches $73 \%$ at $V=0.6 \mathrm{~m} / \mathrm{s}$. This conclusion is especially helpful for the design and optimization of the operating system.

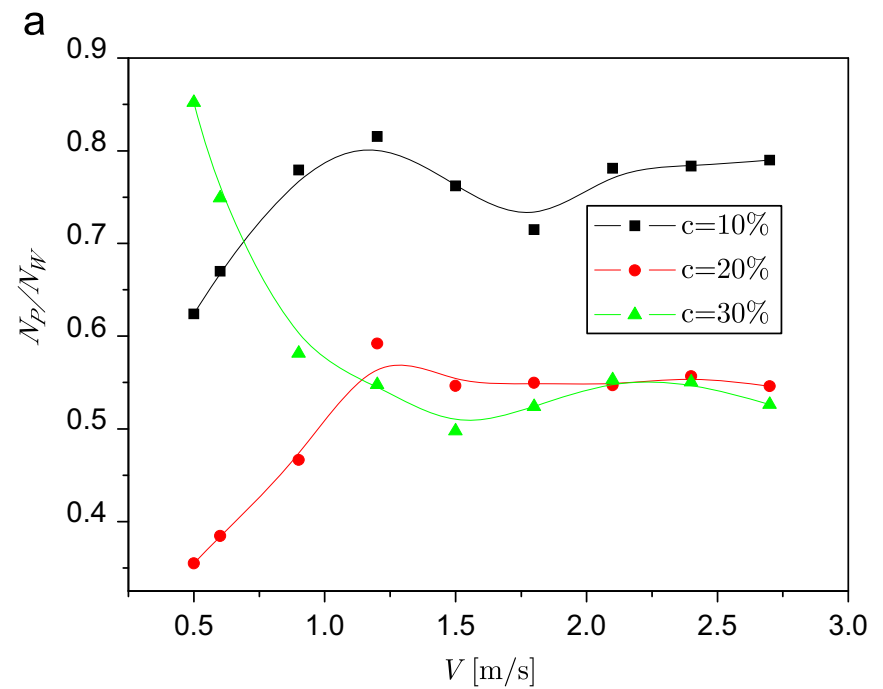

b

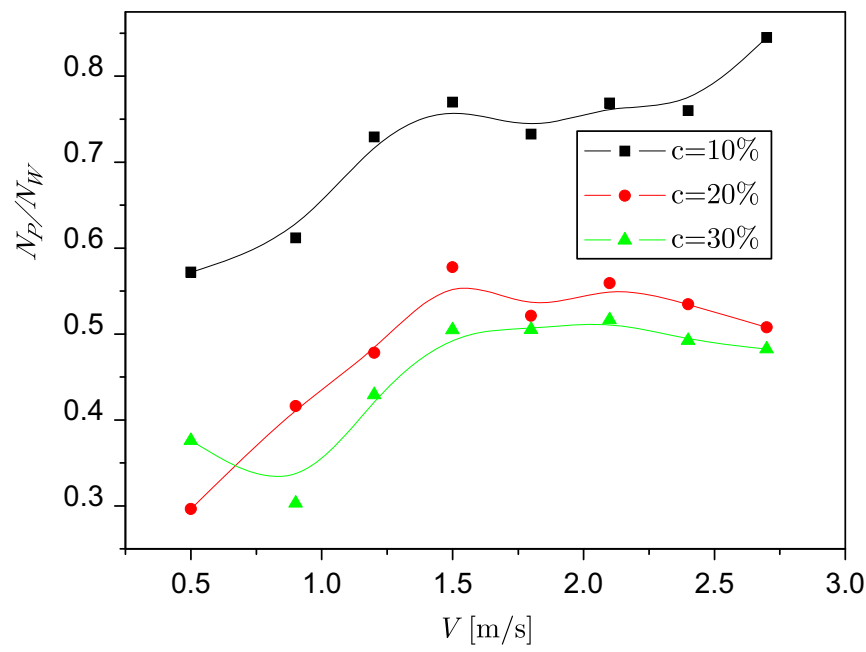

C

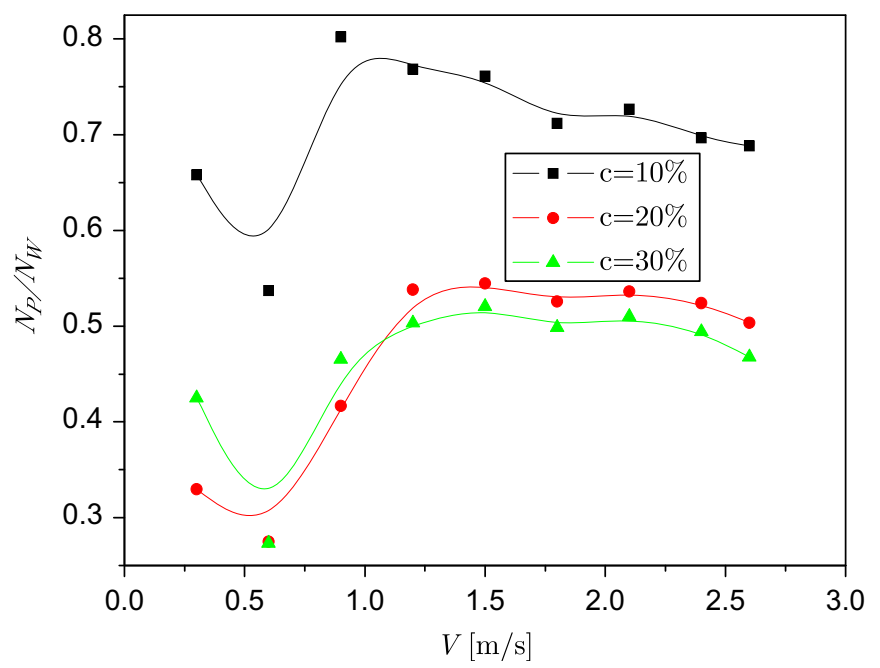

Fig. 5. Relationship of pump consumptions rates and flow velocities. (a) $84^{\circ} \mathrm{C}$, (b) $88^{\circ} \mathrm{C}$ and (c) $92^{\circ} \mathrm{C}$. 


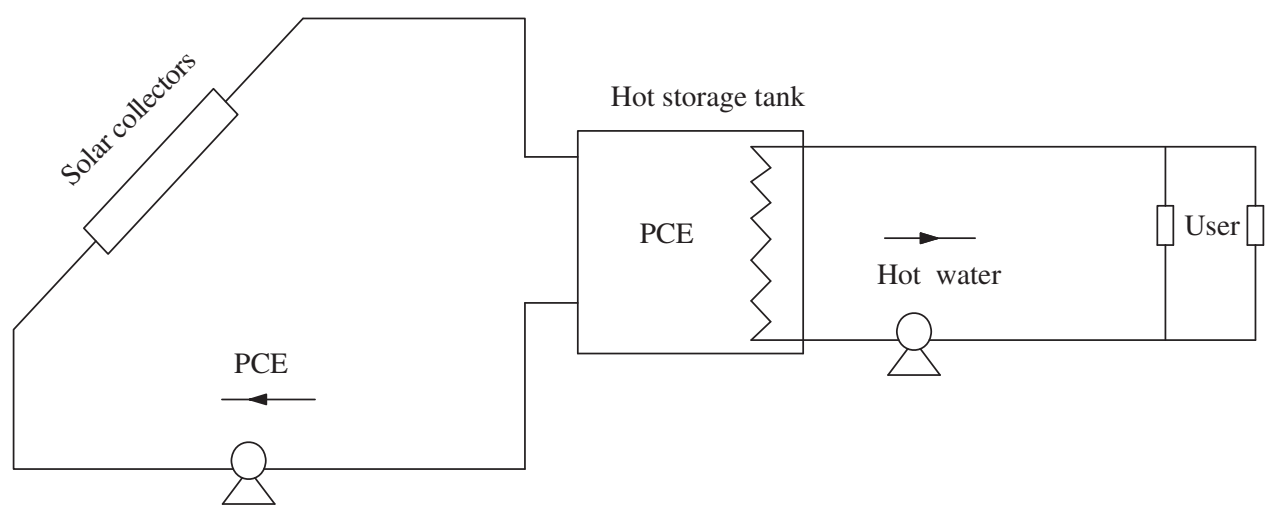

Fig. 6. Application system of the PCE for solar utilization.

\subsection{Application prospect}

Water is widely used as heat storage and transfer media in modern times. Temperature of supply-water and back-water is 95 and $70{ }^{\circ} \mathrm{C}$, respectively, in heating systems in China. The phase change temperature zone of $80-90{ }^{\circ} \mathrm{C}$ is almost in the temperature range of the heating system. So, PCE with melting temperature in this temperature zone can be used for a heating system. Fig. 6 shows the PCE system for solar energy utilization.

PCE was used for heat storage in solar energy utilization; it shows the following advantages: (1) the system with PCE can reduce the volume of the heat storage tanks compared to the system with water for heat storage. As we know, the PCE is mainly made of phase change paraffin and water. So, in the phase change temperature range of PCE, it can not only store or release sensible heat with the help of water contained in the PCE, but also latent heat with the help of paraffin contained in the PCE. Under the condition of storing the same amount of heat, the system with PCE can reduce the volume of the heat storage tanks. (2) The system with PCE can reduce pumping power consumption compared to water as heat transfer media due to latent heat.

In addition, by storing heat at night and releasing the heat in the daytime, the PCE can be used as heat storage media for electrical boiler to peak shift of electrical demands. Furthermore, there is much waste heat discharged from flue gas and water vapor at the phase change temperature zone in industry. PCE can absorb this heat for temporary storage and can be pumped to user to dissipate this heat for later use in its phase change temperature range of $80-90{ }^{\circ} \mathrm{C}$. Compared to water for heat storage and transfer media, the PCE has larger heat storage density and can reduce pumping power consumption in transportation.

Considering the cost of PCE, we chose commercial paraffin as the phase change material, which is cheaper than laboratory grade paraffin. However, the possibility that the benefits of the PCE may outweigh these increased costs still exists. So, the present experimental study in this paper is aimed at investigating the optimum operating conditions including the velocity and the mass concentration to obtain the largest pumping power consumption savings at the lowest costs (the smallest mass concentration).

\section{Conclusions}

A novel PCE as heat storage and heat transfer media for latent heat transfer was prepared.The flow characteristic of the PCE in a horizontal circular tube flow was experimentally investigated.
The following conclusions can be obtained:

(1) The pressure drop of the PCE increases with the increase in mass fraction, and decreases with the rise in temperature, which is affected by the viscosity of the PCE.

(2) The flow rates and the pumping power consumption of the PCE system decrease greatly for the same heat transportation quantity compared with water, due to the latent heat in the process of phase change.

(3) For a given concentration of PCE, there exists a flow velocity that has the largest pumping power consumption savings. This is helpful for the design and optimization of the operating system.

(4) The PCE developed by the authors has good application feasibility in practice.

\section{Acknowledgements}

This work was supported by the Joint Funds of the National Natural Science Foundation of China (Grant number U0634005), National Natural Science Foundation of China (Grant number 50906089), the President Funds of Guangzhou Institute of Energy Conversion, Chinese Academy of Sciences (Grant number 0807rc) and National High Technology Research and Development Program of China (863 Program) (Grant number 2006AA05Z254).

\section{References}

[1] J. Banasze, et al., Numerical analysis of the paraffin wax-air spiral thermal energy storage unit, Applied Thermal Engineering 20 (2000) 323-354.

[2] Bo He, Fredrik Setterwall, Technical grade paraffin waxes as phase change materials for cool thermal storage and cool storage systems capital cost estimation, Energy Conversion and Management 43 (2002) 1709-1723.

[3] Q.Y. Yan, L. Chen, L. Zhang, Experimental study on the thermal storage performance and preparation of paraffin mixtures used in the phase change wall, Solar Energy Materials \& Solar Cells 92 (2008) 1526-1532.

[4] M. Akgun, O. Aydin, K. Kaygusuz, Thermal energy storage performance of paraffin in a novel tube-in-shell system, Applied Thermal Engineering 28 (2008) 405-413.

[5] S. Gschwander, P. Schossig, H.-M. Henning, Micro-encapsulated paraffin in phase-change slurries, Solar Energy Materials \& Solar Cells 89 (2005) 307-315.

[6] J. Li, P. Xue, W.Y. Ding, J.M. Han, G.l. Sun, Micro-encapsulated paraffin/highdensity polyethylene/wood flour composite as form-stable phase change material for thermal energy storage, Solar Energy Materials \& Solar Cells 93 (2009) 1761-1767.

[7] H. Inaba, S. Morita, Flow and cold heat-storage characteristics of phasechange emulsion in a coiled double tube heat exchanger, Journal of Heat Transfer 117 (2) (1995) 440-446.

[8] H. Inaba, S. Morita, Cold heat-release characteristics of phase-change emulsion by air-emulsion direct contact heat exchange method, International Journal of Heat Mass Transfer 39 (9) (1996) 1797-1803.

[9] H. Inaba, C. Dai, A. Horibe, Natural convection heat transfer of microemulsion phase-change-material slurry in rectangular cavities heated from below and cooled from above, International Journal of Heat and Mass Transfer 46 (2003) 4427-4438. 
[10] R. Yang, H. Xu, Y.P. Zhang, Preparation, physical property and thermal physical property of phase change microcapsule slurry and phase change emulsion, Solar Energy Materials \& Solar Cells 80 (4) (2003) 405-416.

[11] X. Wang, Y.P. Zhang, X.X. Hu, Turbulent heat transfer enhancement of microencapsulated phase change material slurries with constant wall heat flux, Journal of Enhanced Heat Transfer 11 (1) (2004) 13-22.

[12] B.J. Chen, X. Wang, Y.P. Zhang, et al., Experimental research on laminar flow performance of phase change emulsion, Applied Thermal Engineering 26 (2006) 1238-1245.

[13] X.X. Hu, Y.P. Zhang, Novel insight and numerical analysis of convective heat transfer enhancement with microencapsulated phase change material slurries: laminar flow in a circular tube with constant heat flux, International Journal of Heat and Mass Transfer 45 (15) (2002) 3163-3172.

[14] Z.N. Zhao, T. Wu, Y.Q. Shi, et al., Investigation on rheology and heat transfer characteristics for a phase change emulsion, Journal of Engineering Thermophysics 22 (5) (2001) 589-592.

[15] Z.N. Zhao, Y.Q. Shi, Y. Zhang, et al., Flow and heat transfer characteristics of phase-change emulsion in a coiled double-tube heat exchanger, Journal of Engineering Thermophysics 23 (6) (2002) 730-732.

[16] L. Royon, G. Guiffant, Heat transfer in paraffin oil/water emulsion involving supercooling phenomenon, Energy Conversion and Management 42 (2001) 2155-2161. 